\title{
Práticas socialmente empreendedoras no setor turístico: análise das condições das Organizações do Terceiro Setor (OTS)
}

\author{
Carlos Morais* \\ Universidade de Trás-os-Montes e Alto Douro (Portugal)
}

\begin{abstract}
Resumo: O turismo é um fenómeno que desperta grande interesse político, muito devido à potencialidade que lhe atribuem na promoção do crescimento económico dos territórios em que se estabelece. O presente estudo procura explorar a noção de empreendedorismo social como mecanismo para a intervenção das OTS no contexto turístico de Cabo Verde. Assente na metodologia qualitativa, o seu principal objetivo foi avaliar as condições do contexto turístico cabo-verdiano, particularmente da ilha da Boa Vista, visando a implementação de iniciativas de empreendedorismo social concebidas por OTS nacionais e locais. Os resultados dão conta de um contexto que se depara com vários problemas sociais e económicos, mas que apresenta, também, recursos e oportunidades suscetíveis de serem valorizadas e potencializadas para fins turísticos, sendo que, o empreendedorismo social é percebido como um mecanismo oportuno para esse fim e, igualmente, um potencial agente de mitigação dos desequilíbrios provocados pelo turismo massificado.
\end{abstract}

Palavras-chave: Empreendedorismo social; Turismo; Sustentabilidade; Organizações do terceiro setor (OTS); Capital social; Capital humano; Capital financeiro.

Socially entrepreneurial practices in the tourism sector: analysis of the conditions of Cape Verdean Third Sector Organizations (OTS)

Abstract: Tourism is a phenomenon that arouses great political interest, largely because of the potential attached to it in promoting the economic growth in destinations. The present study seeks to explore the notion of social entrepreneurship as a mechanism for the intervention of the OTS in the tourism context of Cape Verde. Based on the qualitative methodology, its main objective is to evaluate the conditions of the Cape Verdean tourism context, particularly on the Boa Vista island, aiming the implementation of social entrepreneurship initiatives conceived by national and local OTS. The results show a context that faces several social and economic problems, but also presents resources and opportunities that can be enriched and potentialized for tourism purposes. Social entrepreneurship is perceived as an opportune mechanism for this purpose, and a potential mitigation tool for the imbalances caused by mass tourism.

Keywords: Social entrepreneurship; Tourism; sustainability; Third sector organizations (TSO); Social capital; Human capital; Financial capital.

\section{Introdução}

O turismo é, desde há algumas décadas, um fenómeno cujo registo de crescimento é constante (UNWTO, 2017), facto que faz dele um dos setores mais preponderantes a nível mundial. Embora as deslocações e os contactos entre diferentes povos e culturas tenham feito sempre parte da história da humanidade, o reconhecimento da sua relevância enquanto atividade económica terá generalizado somente a partir da segunda metade do século passado, altura em que um conjunto vasto de transformações - políticas, sociais, económicas, tecnológicas e industriais - viabilizaram a popularização do acesso às viagens e originaram, por consequência, um aumento abrupto do fluxo das viagens.

\footnotetext{
E-mail: c.morais@sapo.cv
} 
A partir de então, esse movimento ganha consistência e não obstante a ocorrência de diversos acontecimentos potencialmente constrangedores dessa ação (crises financeiras, atentados terroristas, desastres naturais, epidemias, etc.), transforma-se num fenómeno de massas. Essa capacidade de resistência, a que se associam as suas tendências de desenvolvimento futuras, levam os mais conceituados organismos habilitados na temática a anteciparem a estabilidade do seu crescimento nas próximas décadas, especialmente em muitos países em desenvolvimento.

Mas essas previsões otimistas esbarram numa crescente vaga de críticas e ceticismo respeitantes às hipóteses desse crescimento ser capaz de se reverter na melhoria efetiva e duradoura das condições de vida das populações recetoras. Na verdade, essas inquietações são conhecidas e remontam ao período posterior à sua consolidação (segunda metade do século XX), quando se verificou que, juntamente com os seus benefícios económicos até então preferencialmente difundidos, os efeitos da atividade turística poderiam, também, gerar impactos negativos (Cunha, 2006; Mourão, 2000). Estudos posteriores comprovaram essas incertezas e demonstraram que os riscos ambientais e os desequilíbrios socioeconómicos associados ao turismo eram superiores em regiões economicamente vulneráveis (Butler, 1999; Saarinen, 2006).

Com efeito, progressivamente universalizou-se a certeza de que teriam que ser feitas diligências para o seu apropriado planeamento, regulamentação e monitorização, de modo a assegurar o seu desenvolvimento sustentável. No entanto, sobretudo enquadrado aos países em desenvolvimento e/ou economicamente vulneráveis, esse padrão "tipo ideal" de turismo é alvo de controvérsias, nomeadamente devido à sua hipotética incompatibilidade com o modelo turístico predominante: turismo de massas/ regime tudo incluído. Ou seja, apesar de se admitir a sua capacidade para melhorar a qualidade de vida humana, o turismo é, simultaneamente, identificado como potencial agente de devastação ambiental, alienação cultural, exclusão e desigualdade socioeconómica, domínio e aproveitamento externo, etc.

Cabo Verde, na qualidade de "país de desenvolvimento médio", incorre no espaço de exteriorização desses problemas. Tendo visto reconhecidas internacionalmente as suas potencialidades turísticas, o governo designou, no início dos anos 90, esse setor como estratégico e prioritário para mitigar as suas debilidades socioeconómicas, entre os quais a pobreza. Desde então, as forças do setor público foram substancialmente concentradas na captação de investimentos estrangeiros para o país, que foi admitindo a construção sucessiva e descontrolada de unidades hoteleiras de grandes dimensões. Essa afluência estabeleceu-se inicialmente na ilha do Sal, e lá manteve-se centralizada até aproximadamente uma década atrás, altura em que a ilha da Boa Vista também adquiriu protagonismo nesse campo, decorrente da aposta governamental na melhoria das condições de acesso aéreo.

Como resultado, Cabo Verde viu a sua procura turística aumentar exponencialmente e a contribuição da atividade para o PIB ser atualmente estimada na ordem dos 21\% (INECV, 2015). Porém, o país apresenta hoje um quadro geral contraditório: se, por um lado, a economia cresceu, e a pobreza decresceu, por outro lado, as desigualdades sociais, as taxas de desemprego e de precariedade laboral propagaram-se. Essa situação evidencia-se mormente na ilha da Boa Vista onde, a título ilustrativo, a maioria dos colaboradores dos estabelecimentos turísticos tem baixa qualificação técnica e reside num bairro ilegal e degradado.

Em muitos contextos internacionais identicamente fustigados por problemas sociais, vão emergindo iniciativas socialmente empreendedoras para lhes fazer face. À semelhança do turismo, o empreendedorismo social está em franco crescimento. Ao sublinhar, como seu fim último, a geração de impacto social e a transformação do contexto alvo de intervenção, esse fenómeno concorre, em parte, para o desenvolvimento sustentável dos territórios.

Este estudo decorre, assim, na sequência de duas circunstâncias concomitantes: por um lado, da constatação da conjuntura turística e socioeconómica do país e da Boa Vista acima exposta. Por outro lado, da perceção inicial - posteriormente reforçada ante os resultados das pesquisas exploratórias - de fraca familiaridade com o conceito de empreendedorismo social no país. Em fase dessa situação, o problema de pesquisa focaliza-se nas articulações entre turismo (sustentável), o empreendedorismo social, e o papel que as organizações do terceiro setor (OTS) podem desempenhar a este respeito.

O seu objetivo principal é avaliar as condições do contexto turístico cabo-verdiano e boa-vistense, sondando nesse quadro as perspetivas para implementação de iniciativas de empreendedorismo social concebidas por OTS. Como objetivos específicos propõe-se aferir se as OTS estão munidas de capital social, capital humano e capital financeiro, tidos como recursos essenciais para se empreender socialmente. A sua finalidade é fornecer pistas para um desenvolvimento turístico sustentável de Cabo Verde, particularmente da ilha da Boa Vista, através da disseminação do empreendedorismo social no setor e no país. 


\section{Empreendedorismo social: origem, conceito e fatores críticos de sucesso}

À semelhança do turismo, o empreendedorismo social é um fenómeno em franco crescimento, que atrai cada vez mais atenção dos mais variados setores da sociedade. Enquanto conceito, a sua emergência ocorre nos anos 80 do século XX nos EUA, mas só se propaga na década seguinte, como designação para qualificar as soluções e lógicas de intervenção adotadas por cidadãos e sociedade civil em geral para atacar os problemas sociais que se escapavam do raio de ação quer dos Estados quer do mercado, por desconsideração ou inaptidão (Parente, 2014).

A literatura académica está repleta de definições do empreendedorismo social, facto que talvez dá razão a Dees (2001), que o vê como um conceito que continua a ter um significado diferente para diferentes pessoas e investigadores. É precisamente esse autor quem terá concebido uma das definições mais completas e clássicas do conceito de Empreendedorismo Social, ao afirmar que são empreendedores sociais os indivíduos que são agentes de mudança no setor social, inovando, criando novas oportunidades (Dees, 2001). Mair e Martí (2006) definiram-no operacionalmente como um processo que envolve o uso e a combinação inovadora de recursos na procura de oportunidades para a criação de valor social, que catalisem mudanças sociais e/ou atendem a necessidades sociais. Esse processo não distingue a oferta de serviços de produtos, que pode suceder numa organização nova ou numa já existente.

A diversidade de perspetivas motivou também Brooks (2008) a reunir um conjunto de argumentos e aspetos que, segundo ele, estão presentes em praticamente todas as definições desencadeadas pelos principais investigadores da área: 1) o empreendedorismo social visa a resolução de problemas ou necessidades sociais não satisfeitas nem pelo setor privado nem pelo público; 2) é, principalmente, motivado pelo benefício social; 3) trabalha, geralmente, com (e não contra) as forças do mercado. Brouard \& Larivet (2009) também analisaram um conjunto de definições do empreendedorismo social, no intuito de sublinhar as suas principais caraterísticas, mormente, representa uma variedade de atividades e processos; quer criar e manter valor social; incentiva mais abordagens empreendedoras para o uso social; revela vários níveis de inovação e mudança; e é limitado pelo meio envolvente.

Constata-se, assim, que o foco no valor social é constante e transversal às várias definições de empreendedorismo social (Certo \& Miller, 2008). Nesse caso, é legítimo questionar: o que representa objetivamente o valor social que é suposto ser produzido pelo empreendedorismo social? Este exercício é particularmente difícil, uma vez que o social é uma categoria extremamente complexa e contestada (Nicholls \& Cho, 2006).

Young (2006) também concorda que a contestabilidade é uma das caraterísticas do valor social porque reúne elementos incomensuráveis e outros que não podem ser facilmente agregados em uma única métrica. É ainda caraterizado pela subjetividade (pois os processos de consumo, participação e co-construção dependem das experiências de vida, e estão intimamente associados aos seus efeitos); pela heterogeneidade (resulta de processo negociado entre os stakeholders); pela contingência (na medida em que é incerto e está sempre aberto a reavaliação); e pelos valores básicos da vida, que são inseparáveis quando se trata de atividades sociais. Segundo a autora, o valor social só ganha sentido se beneficiar e for reconhecido pelo público-alvo da intervenção.

Em suma, pode-se afirmar que a configuração atual do empreendedorismo social assume uma nova resposta social, que envolve todos os setores de atividade, numa lógica inovadora, mercantil e sustentável - e não assistencialista, como era (ou ainda é) prática - para pôr fim aos problemas sociais da humanidade, para os quais ainda não existem respostas, ou, se existem, são ineficazes.

Com o conceito melhor elucidado, importa perceber quais os fatores essenciais e necessários para alavancar e sustentar uma iniciativa que se queira socialmente empreendedora. É verdade que no meio académico não abundam estudos sobre essa questão. Todavia, invocando o facto de que o empreendedorismo social emana do empreendedorismo tradicional, admite-se que parte dos seus elementos são análogos.

Com base nessa premissa, importa assinalar o modelo analítico PCDO (Person, Context, Deal, Opportunity) de Sahlman (1996), um paradigma do empreendedorismo social. De forma a ajustar o modelo PCDO ao empreendedorismo social, a variável Negócios foi substituída pela variável Proposição de Valor Social, para dar centralidade à missão social desse tipo de organizações. De igual modo, os recursos económicos e humanos passam a ser observados separadamente. Conforme ilustra a figura seguinte, o cruzamento dos três círculos (opportunity, people e capital) reflete a sobreposição e a interdependência que os carateriza, funcionando a variável Social Value Proposition como elemento de integração. À volta acham-se as forças contextuais que moldam as variáveis e que exigem atenção permanente do empreendedor social. 


\section{Figura 1: estrutura do empreendedorismo social}

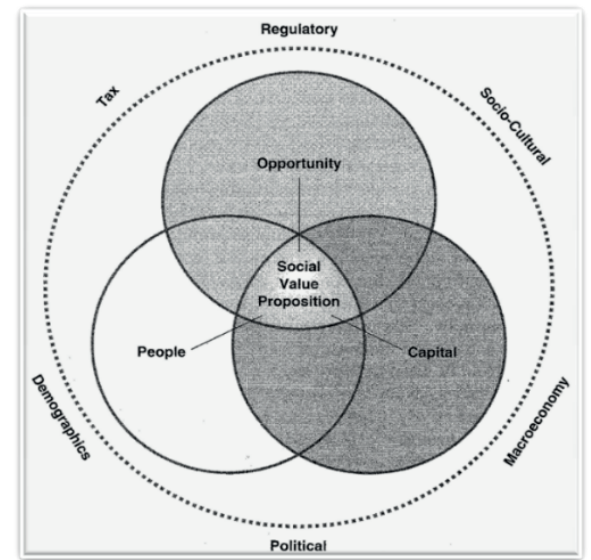

Fonte: Austin et al., 2006

A efetiva criação de valor social exige alinhamento organizacional externo e interno entre todos as componentes-chave da estrutura. Igualmente importante é o trabalho em rede. Embora possam existir barreiras naturais à colaboração extra organizacional, regra geral os problemas sociais exigem muito mais recursos do que aquilo que uma única organização é capaz de mobilizar. Com efeito, porque a essência do empreendedorismo social é produzir valor que gere impacto social, a trabalho colaborativo é uma boa forma de o conseguir (Austin et al., 2006).

Para Leadbeater (1997), o sucesso de uma organização socialmente empreendedora é altamente dependente do contributo e capacidade em investir e criar capital social, isto é, de redes de relacionamentos assentes na cooperação, confiança e partilha de valores, capazes de sustentar as parcerias e alianças necessárias para a resolução de problemas que isoladamente são intransponíveis.

A relevância atribuída ao capital humano e capital financeiro é axiomática, mas também é notória a proeminência que os mais variados autores (Portes, 2000; Mair \& Martí, 2006; Hill \& Cooke, 2013; Putnam, 1995) conferem ao capital social no processo do empreendedorismo social.

Woolcock e Narayan (2000) formularam o capital social como constituído por três dimensões bonding, bridging e linking, e conforme Mignone \& O’Neil (2005), esta distinção ajuda a apreendê-lo melhor quando se está na presença de um estudo qualitativo. Devido à sua natureza multidimensional e, em certa medida, ambígua, a tarefa de medir os níveis de capital social de uma organização ou sociedade é complexa (Woolcock \& Narayan, 2000). Por outro lado, embora possa favorecer o sucesso do empreendedorismo social, os seus efeitos também podem ser inversos e indesejáveis (Portes, 2000; Woolcock \& Narayan, 2000), como por exemplo o risco de excessiva dependência (Mair e Martí, 2006).

De resto, o capital social está diretamente ligado a mais duas valências, igualmente importantes ao empreendedorismo social. A primeira tem a ver com a correlação que alguns autores fazem entre o background e o empreendedorismo social. Na verdade, a erudição dos agentes que desencadeiam um processo dessa natureza pode não ser requisito obrigatório, mas é, certamente, indispensável. Aliás, a prática revela uma forte presença de agentes altamente qualificados no empreendedorismo social (Ferreira, 2005, 2006; Bernardino \& Santos, 2014). O segundo aspeto refere-se à vanguarda desse tipo de iniciativas. Do ponto de vista organizacional, o empreendedorismo social é um processo que pressupõe uma liderança participativa, capaz de mobilizar, integrar e coordenar indivíduos e instituições, aproveitar as suas complementaridades e contribuições, visando atingir um impacto coletivo (Leadbeater, 1997; Mair \& Marti, 2006; Peredo \& MacLean, 2006; Parente, 2014; Bornstein, 2005).

Ora, em virtude da sua potencialidade em combinar retorno económico e impacto social, o turismo configura-se como um setor capaz de propiciar um ambiente favorável à constituição, desenvolvimento e sustentação de iniciativas de empreendedorismo social e, consequentemente, poder assumir-se como um meio privilegiado de interação entre turistas e comunidades locais - o que, geralmente, não acontece nos destinos massificados -, e, principalmente, estabelecer-se como um válido instrumento 
de compensação dos desequilíbrios socioeconómicos que o modelo de turismo hegemónico gera, muito devido à sua orientação para o lucro a curto prazo.

Partindo desta problemática, o presente artigo pretende debater o potencial que o turismo, desenvolvido com base em iniciativas de empreendedorismo social e orientadas por princípios de sustentabilidade socioeconómica, cultural e ambiental, pode representar para um desenvolvimento socioeconómico e inclusivo em Cabo Verde.

\section{Metodologia}

O presente trabalho interroga-se justamente sobre as condições de desenvolvimento de iniciativas de empreendedorismo social no setor turístico em Cabo Verde e, em particular, na ilha da Boa Vista. Para esse efeito, procura, em primeiro lugar, analisar o padrão de desenvolvimento turístico do país e da ilha para, com base num diagnóstico das tendências, dos recursos existentes e das expetativas e perceções dos atores locais, aferir das condições e dinâmicas observáveis no terreno, e em especial entre as OTS e o seu raio de ação, se revelam mais ou menos favoráveis à emergência e ao desenvolvimento de iniciativas suportadas por princípios, metas e formas de intervenção caraterísticas do empreendedorismo social. Trata-se, por outras palavras, de sondar em que medida se observam no terreno condições e dinâmicas favoráveis ao desenvolvimento de iniciativas no setor turístico alternativas ao que tem sido o modelo dominante e mais orientadas para o envolvimento das populações locais na resolução de problemas locais, nomeadamente de desenvolvimento socioeconómico sustentável sensíveis seja ao respeito pelas culturas locais, seja à promoção da qualidade de vida das populações locais.

Entendendo-se que as OTS são as entidades que estão mais bem posicionadas para atuar neste domínio, que têm, regra geral, motivações filantrópicas, e que se intensifica a ideia de que, para assegurarem a eficácia das suas missões sociais, precisam adotar mecanismos organizacionais e de funcionamento mais próximos dos do setor empresarial, a pesquisa privilegia a análise das condições que estas reúnem do ponto de vista do capital social, humano e financeiro, perspetivados como recursos primários e fundamentais para se empreender socialmente.

A pesquisa focaliza-se, portanto, nas articulações entre o empreendedorismo social e o turismo, no sentido de perceber se as atuais condições do contexto turístico cabo-verdiano favorecem a viabilidade e o êxito de eventuais iniciativas de empreendedorismo social das OTS, especialmente na ilha da Boa Vista.

O seu objetivo geral é analisar se o contexto turístico cabo-verdiano é propício para a implementação de iniciativas de empreendedorismo social, por parte das organizações do terceiro setor (OTS). Como objetivos específicos propõe-se aferir se as OTS estão munidas de capital social, capital humano e capital financeiro, tidos como recursos primários para se empreender socialmente.

$\mathrm{O}$ objeto de estudo foi problematizado em torno de dois níveis analíticos: macro e micro. A nível macrossocial, recorreu-se à técnica da entrevista para captar a opinião dos agentes nacionais e locais relevantes na área, sobre diversas questões especificamente relacionadas com as dinâmicas de desenvolvimento turístico, nomeadamente no que toca à conjuntura atual e perspetivas de evolução futuras, sua sustentabilidade, seus impactos negativos e positivos, e caraterísticas do tipo de turismo predominante. A nível microssocial, a proposta teórica foi estruturada a partir da ideia de que a compreensão das dinâmicas de empreendedorismo social e das condições que o podem favorecer exige que se sondem os recursos primários que o podem impulsionar: capital social, capital humano e capital financeiro. Nesse sentido, a pesquisa procurou avaliar as condições reunidas pelas OTS nesses planos.

No plano metodológico, adotou-se uma estratégia de cariz predominantemente qualitativa. Esta estratégia afigurou-se a mais adequada a um trabalho que procura captar as dinâmicas que emergem das relações sociais (Flick, 2009), que se debruça sobre o funcionamento organizacional (Strauss \& Corbin, 2008) e que procura, de forma minuciosa, empática e imparcial, conhecer as perspetivas dos intervenientes diretos do processo (Miles et al., 2014).

Quanto à sua profundidade, entende-se que esta investigação é descritiva e exploratória, dado a inexistência de estudos que interrelacionam o empreendedorismo social e o turismo no arquipélago cabo-verdiano e os objetivos centrais do estudo, que procura combinar um diagnóstico da situação com uma sondagem das perspetivas e condições de desenvolvimento de uma certa linha de ação: o empreendedorismo social no setor turístico.

A recolha dos dados e informações necessárias foi feita com recurso à triangulação dos seguintes instrumentos e técnicas: 1) entrevistas semiestruturadas a informadores privilegiados e interlocutores locais; 2) análise documental, de dados estatísticos, estudos académicos, planos públicos de políticas 
estratégicas para as áreas de turismo e desenvolvimento local, e outras publicações disponíveis; 3) observação participante no terreno.

Foram contatados e entrevistados quinze (15) interlocutores do setor público (Ministério do Turismo, Direção-geral da Solidariedade Social, Câmara Municipal da Boa Vista, Sociedade de Desenvolvimento Turístico das ilhas da Boa Vista e do Maio, Serviços descentralizados do Estado), do setor privado (unidades hoteleiras e outras empresas do ramo turístico), do terceiro setor (associações comunitárias e ONG), e ainda alguns residentes na Boa Vista, considerados relevantes na sequência do desenvolvimento da pesquisa no terreno. As questões que constituíram o guião eram, grosso modo, as mesmas para todos os entrevistados. Porém, algumas assumiram cunho de exclusividade, tendo em vista a peculiaridade da área de intervenção e atribuições dos entrevistados. Os dados resultantes das entrevistas foram tratadas através da análise de conteúdo, assistida pelo programa informático MAXQDA.

\section{Resultados da pesquisa}

Este ponto incorpora a componente empírica do estudo que, sendo exploratório, aborda questões relacionados com a intervenção social e local, e compreendendo o empreendedorismo social e o turismo sustentável como conceitos que se fundamentam em princípios inerentes à participação e à coprodução, considerou-se adequado apreender os diversos pontos de vistas sobre o objeto de estudo em questão. Assim, a partir de uma abordagem centrada nas principais instituições e agentes de intervenção nacional e local, procurou-se aprofundar o conhecimento sobre o desenvolvimento turístico e o papel que nele pode representar os projetos de empreendedorismo social das OTS. Sequencialmente, propôs-se analisar criticamente os processos organizacionais das OTS, seus recursos, competências e propensão para o envolvimento em atuações articuladas.

\subsection{Nível macro - contexto turístico perspetivado pelos protagonistas locais}

Da análise do conteúdo das entrevistas infere-se que a avaliação que os entrevistados fazem do contexto turístico atual do país é, em primeiro lugar, condizente com o quadro traçado por Brohman (1996), que identifica um conjunto de problemas comuns aos países do chamado Terceiro Mundo que optaram pela adoção de estratégias de desenvolvimento viradas para o exterior, incluindo a excessiva dependência estrangeira, desarticulação entre o turismo e a produção económica nacional, desigualdades socioeconómicas e espaciais, degradação ambiental e perceção de perda de identidade cultural e controlo social. Em conformidade com a tese desse autor, em Cabo Verde esses constrangimentos também advêm principalmente da fraca participação comunitária no planeamento e desenvolvimento turístico, processo que vem seguindo um sentido top-down. Os custos e os benefícios do turismo estão, pois, desproporcionadamente repartidos, com consequências diretas no acentuar dos desequilíbrios regionais e locais próprios de um país insular e economicamente débil, onde a pobreza, a desigualdade social, a precariedade habitacional e o desemprego distinguem-se entre tantos problemas sociais.

Entre os entrevistados sobressai a perceção de que modelo de desenvolvimento turístico de massas experimentado no Sal e posteriormente na Boa Vista - consubstanciado pelo regime "tudo incluído" - gera importantes retornos económicos, porém insuficientes para justificar os seus custos e impactos sociais e ambientais negativos. As decorrências desse modelo, o deficiente planeamento turístico e o distanciamento ou o fraco comprometimento da população local no processo de desenvolvimento turístico além de não favorecerem o desenvolvimento do turismo cultural e outras modalidades de turismo alternativo, constituem os principais entraves ao surgimento de atividades empreendedoras de iniciativa local, mercê do senso comum em como qualquer eventual projeto tem, à partida, poucas hipóteses de sucesso. Insuficiências respeitantes ao espírito empreendedor, acesso ao crédito e incentivos públicos integram o rol das causas mais difundidas para esse ceticismo. As evidências levam a crer, contudo, que a sua origem está antes diretamente relacionada com a marginalização política da população local em matéria de turismo, mas também, e principalmente, com o relacionamento frágil e instável que se assiste entre esta e os principais operadores turísticos, cuja postura tem sido, no geral, marcadamente introvertida.

A análise do contexto turístico nacional e local possibilitou identificar, contudo, um conjunto de oportunidades através dos quais poderão ser suportadas iniciativas de empreendedorismo social, cujos processos de desenvolvimentos poderão passar por três diferentes estratégias de participação: 1) envolvimento direto dos turistas (colaboração das empresas e/ou operadoras turísticas poderá não ser indispensável); 2) envolvimento direto das empresas e operadoras turísticas (aqui os turistas assumirão um papel complementar); 3) ou ainda com a implicação expressa e simultânea de ambos. 
No primeiro, em que se pressupõe a oferta de produtos e/ou serviços a turistas, a garantia de qualidade e o significado simbólico desses, por um lado, e as capacidades de marketing da organização promotora, por outro, são os principais requisitos para que se possa estimular o desejo de compra nos turistas que, em regra, estão hospedados nos resorts "tudo incluído". A par do Sol e Mar, Turismo Náutico, Turismo de Natureza (Ecoturismo), Turismo no Espaço Rural e Turismo Cultural emergem como os produtos turísticos com maior potencial de desenvolvimento. Pode-se incluir aqui a valorização turística de um conjunto de recursos que na ilha da Boa Vista permanecem desconhecidas ou subaproveitados, como a observação das espécies endémicas, musealização do património histórico e cultural, organização de excursões culturais e históricas (ex. passeios de burro), recuperação e valorização da gastronomia típica, edificação de alojamentos turísticos comunitários ou hospedagem de turistas em casas particulares (economia partilhada), etc. A conceção de um projeto que interligue os hotéis da ilha que atualmente vazam grande quantidade de lixo orgânico numa lixeira a céu aberto e as cerca de meia centena de pessoas que os recolhem para alimentarem os seus porcos, é um exemplo de proposta (suinicultura) que se pode enquadrar na segunda estratégia. Ao invés de viverem na lixeira, essas pessoas poderiam fazer a recolha dos restos orgânicos de forma profissionalizada e nos próprios hotéis, e posteriormente contratualizar a venda da carne aos hotéis, que desta forma deixariam de importar carne de porco.

Praticamente todos os entrevistados são de opinião que a incorporação de iniciativas socialmente empreendedoras no setor turístico nacional, especialmente na Boa Vista, entrevê-se propícia e pertinente para a resposta aos problemas sociais patentes e concomitantemente contribuir para que o turismo seja efetivamente mais sustentável.

\subsection{Nível micro - o terreno de atuação das OTS, recursos e condições para o empreendedorismo social no setor turistico}

Este estudo procurou sondar as condições, os recursos e a disponibilidade existentes no seio das OTS cabo-verdianas, e em particular na ilha da Boa Vista, para o desenvolvimento de iniciativas de empreendedorismo social no setor turístico ou em atividades associadas a esse setor. Para esse efeito, a análise apresentada nesta parte pondera essas condições e recursos nos três domínios que atrás se defendeu serem fundamentais para a emergência e o desenvolvimento de iniciativas de empreendedorismo social: o capital humano, social e financeiro. Partindo da constatação, que a pesquisa empírica confirmou, de que a ideia e os princípios do empreendedorismo social se encontram pouco difundidos e enraizados na prática das OTS locais, a análise procura essencialmente avaliar em que medida o tecido de atores locais acumula condições e se revela favorável ao desenvolvimento de iniciativas mais enquadradas pelos princípios da economia social e do empreendedorismo social e, por essa via, à construção de alternativas ao modelo predominante no setor turístico, que, como se viu atrás, revela muitas limitações e aspetos críticos, nomeadamente no que se refere aos benefícios para as populações locais e ao respeito pelos valores da sustentabilidade sociocultural e ambiental.

Em pano de fundo, esta análise procura, por isso também, questionar as perspetivas dos atores locais em relação ao tipo de atuação a desenvolver no setor, o seu posicionamento face às potencialidades de formas de atuação mais típicas do empreendedorismo social e a sua disponibilidade para esse efeito.

\subsubsection{Capital humano}

Em termos de capital humano a nível nacional, salienta-se a aposta que o país tem vindo a fazer na educação e no desenvolvimento dos recursos humanos desde a independência. No entanto, o terceiro setor do país não tem sido capaz de tirar mais e melhores proveitos desse investimento de forma a atrair novos recursos humanos para o campo da intervenção social. Sucede, deste modo, que são raras as OTS cabo-verdianas com estruturas organizacionais profissionalizadas para os cargos de gestão. Manter aqueles que nele labutam, seja em regime subordinado, seja em voluntariado, também não tem sido fácil. Embora os membros das OTS nacionais - mormente as das ilhas de Santiago e São Vicente - tenham beneficiado de sucessivas ações de formação e capacitação em vários domínios, regra geral os seus contributos são interrompidos assim que surgem oportunidades profissionais consideradas mais vantajosas.

A insuficiência de recursos humanos devidamente qualificados para a intervenção no campo da economia social é a mais importante das debilidades das OTS nacionais, que têm no exercício da liderança, elemento considerado fundamental para o fomento do empreendedorismo social (conforme Leadbeater, 1997; Mair \& Marti, 2006; Peredo \& MacLean, 2006; Parente, 2014; Bornstein, 2005 e Alvord et al., 2004), a sua principal deficiência. Na Boa Vista essa realidade é ainda mais acentuada, uma vez que a própria dinâmica associativa na área social é fraca, e mesmo em duas ou três OTS tidas 
como as mais interventivas, são identificadas diversas lacunas de natureza estrutural e organizacional, nomeadamente a recorrente prática de lideranças individualizadas - em regra centralizadas na figura do presidente da direção - e prolongadas, a acumulação de funções, o incumprimento dos estatutos e regulamentos, a inoperância dos órgãos sociais com competências deliberativas e fiscalização (Assembleia Geral e Conselho Fiscal), a falta de planeamento estratégico e de mecanismo de avaliação de impactos e responsabilização, etc.

Ou seja, a gestão das OTS processa-se ainda num quadro de voluntariedade e informalidade generalizada, igualmente caraterizada por baixos níveis de escolarização e qualificação técnica dos seus membros. Manifestamente essas condições acabam por limitar as suas capacidades de captação de recursos, designadamente junto de organismos internacionais.

Os entrevistados são, pois, unânimes em considerar que atualmente em Cabo Verde apenas um reduzido número de OTS estão minimamente apetrechadas de recursos humanos com as competências necessárias para a dinamização da economia social no setor turístico. E mesmo estas não as possuem em números suficientes.

O reforço da capacidade organizativa e gestionária das OTS, quer em termos quantitativos quer qualitativos, é, pois, impreterível. A propósito, argumenta Ferreira (2006) que, considerando a diversidade de exigências cada vez mais crescentes e específicas que se impõem às organizações que a nível mundial operam no setor da economia social, atuar no domínio do empreendedorismo social constitui um desafio novo e árduo. De modo que o êxito nessa missão só será assegurado se os agentes e as organizações promotoras forem capazes de se manterem constantemente qualificados e adaptados às mudanças que vão ocorrendo no meio envolvente. Ou seja, as estruturas de gestão das OTS devem ser profissionalizadas, pois, tal como adverte Meneses (2012, p. 137), "Sem uma liderança competente as organizações sem fins lucrativos perdem eficiência, eficácia e impacte social”.

\subsubsection{Capital social}

Em matéria de capital social, a análise aponta para uma reduzida participação cívica e associativa dos cabo-verdianos. Em Cabo Verde a ação coletiva na área social estabeleceu-se, de acordo com as teses de Carvalho (2008) e Santos (2013), fundamentalmente através do cooperativismo e do associativismo. Enquanto o primeiro foi um importante pilar de desenvolvimento do país entre 1975 a 1990, o segundo ganhou dinamismo a partir de 1990, altura em que ocorreu a abertura política, e consolidou-se a partir do ano 2000 (Santos, 2013). Todavia, embora haja atualmente OTS de diversas formas jurídicas disseminadas em praticamente todas as ilhas, algumas das quais com reconhecido protagonismo e impacto local, a participação dos cabo-verdianos - uma vez mais com destaque negativo para os boa-vistenses - em atividades sociais e coletivas é considerada bastante fraca.

Além da baixa percentagem de cidadãos cabo-verdianos e boa-vistenses filiados em OTS, o nível de comprometimento e ativismo daqueles que são membros é igualmente ténue. Visto que no país prevalece "um ambiente legislativo favorável à criação de associações e organismos da sociedade civil" (UECV, 2014, p. 2), essa crise do associativismo pode-se explicar por mudanças de atitudes, comportamentos, princípios e valores outrora norteadores do modelo societal cabo-verdiano que se foram desvanecendo ao longo dos últimos anos, no qual a solidariedade coletiva e os interesses comunitários tinham primazia. Essa realidade corrobora-se, singelamente, pelo junta $\mathrm{mom}^{1}$, expressão que simbolizou o caráter solidário, cooperante e associativo da sociedade civil cabo-verdiana em tempos passados, designadamente nas diversas ações conjuntas que se levou a cabo na luta contra pobreza, pela sobrevivência em épocas de estiagem, pela independência do país, e no próprio processo de construção do Estado. Esse fenómeno subsiste, mas certamente com menos regularidade.

Essas alterações dos padrões comportamentais estão inerentemente associadas a alguns fatores cujos efeitos possivelmente concorrem para a alienação associativa que hoje se assiste. Refira-se aqui, em primeiro lugar e especificamente ao caso da ilha da Boa Vista, o boom demográfico e a subsequente descaraterização cultural, decorrentes da aposta desenfreada no turismo sem a devida atenção aos equilíbrios sociais. Até cerca de uma década atrás, Boa Vista era uma ilha onde praticamente todos os seus habitantes, por mais afastadas que fossem as suas áreas de residência, se conheciam e se relacionavam costumeiramente. Nessa altura as relações sociais eram, à conta disso, mais compactas, e as normas sociais, particularmente a de reciprocidade, mais valorizadas e, logo, mais eficazes. São disso exemplo as divergências que nos últimos anos opõem os criadores de gado e os agricultores locais após as sementeiras de sequeiro. Antigamente esse problema não se colocava, porque quer as normas quer as sanções morais e sociais para os incumpridores eram respeitadas. 
De facto, Coleman (citado por Almeida, 2011) deu conta da relevância das redes sociais para o âmbito do capital social numa das suas publicações, na qual concluiu que, comparativamente às redes abertas, as redes fechadas são mais profícuas na efetivação de ações coletivas. As transformações desencadeadas pela aposta no turismo na ilha levaram, ainda, ao agravamento das desigualdades socioeconómicas entre os boa-vistenses e das disparidades entre estes e os organismos públicos e privados, favorecendo assim uma maior verticalização das relações sociais. Conforme Almeida (2011), as comunidades assentes em vínculos predominantemente verticais tendem a ter índices de confiança mútua baixos e insuficientes para alavancar a cooperação e a coesão social.

Um segundo aspeto reporta-se à matriz económica predominantemente capitalista que se instituiu no país, especialmente nos anos que se seguiram à sua abertura económica, acarretando lógicas e instrumentos de regulação da vida económica e social novos e marcados pela competição e maximização do lucro. Com efeito, a reciprocidade e a solidariedade tradicionalmente bem vincadas nas relações económicas, sociais e humanas foram suplantadas pelo individualismo e força do capital financeiro.

A terceira causa atribui-se ao desinteresse das autoridades públicas nacionais e locais em sensibilizar as populações para as mais-valias do associativismo. O próprio sistema democrático representativo vigente no país inibe, em certa medida, a maior participação social e política dos cidadãos, uma vez que legitima a centralização política e decisória quase exclusivamente nos partidos eleitos.

Acrescenta-se ainda a bipolarização e o bipartidarismo do país, fatores que têm contribuído para partidarizar a sociedade cabo-verdiana de tal forma que qualquer iniciativa associativa manifestamente independente e idónea que emerja seja objeto de tentativas de instrumentalização político-partidário ou, em último recurso, de desmobilização. Não é coincidência a gestão de algumas OTS do país estarem ao cargo de militantes ativos de partidos políticos, não obstante essa conduta ser reprovada pelo Código de Ética das OTS cabo-verdianas (PLATONGS, 2009). Essa monopolização das associações sociais para fins políticos e eleitoralista constitui, de facto, uma evidência em como, tal como sublinhado por Putnam (1993), Portes (2000), Almeida (2011) e outros autores, o capital social pode também ser usufruído para fins inadequados.

O cenário de fragmentação do país reflete-se também na dispersão e, nalguns casos, sobreposição de esforços por parte das entidades públicas nacionais e locais, nomeadamente no domínio da intervenção social. Embora algumas melhorias tenham vindo a ser registadas nesse capítulo, o facto é que, ainda assim, não existe no país uma cultura de articulação e trabalho em rede. E isso tem subjacente alguma falta de confiança - "uma componente essencial do capital social" (Putnam, 1993, p. 169) - transversal aos cidadãos, OTS, instituições privadas e públicas, sinalizada pela reduzida participação e intercâmbio associativo, como anteriormente mencionado, mas também, em certa medida, pelas elevadas taxas de abstenção eleitoral e o crescente índice de corrupção percebida ${ }^{2}$.

E numa sociedade com poucas oportunidades de participação política e baixos níveis de consciência e confiança cívica, a mobilização coletiva para a assunção de responsabilidades sociais tende a ser escassa. Boa Vista é disso um caso paradigmático. Embora a população em geral reconheça que a situação social tem vindo a deteriorar-se progressivamente, e que o poder público tem sido ineficaz no cumprimento das suas funções sociais, não se avista na ilha um terceiro setor estruturado e ativo como se suporia expetável.

Para se aferir dos níveis de capital social das OTS nacionais, procurou-se também sondar as suas dinâmicas de intervenção, bem como suas capacidades de mobilização de parceiros e recursos, tendo em ambos sido verificados padrões muito reduzidos. A título ilustrativo, a observação e as entrevistas sugerem que raramente as OTS conseguem comparticipar os seus projetos sociais, o que constitui um dos principais requisitos da maioria dos concursos internacionais para a atribuição de subvenções.

Pode-se, portanto, inferir que, grosso modo, os níveis de capital social das OTS cabo-verdianas são baixos. Particularmente no que diz respeito às dimensões do capital social, tal como definido por Woolcock \& Narayan (2000) e Mignone \& O'Neil (2005), o linking capital, representado neste estudo pelas ligações e interações com instituições e congéneres estrangeiras, é um ponto fraco das OTS nacionais. O bridging capital, observado pelos vínculos estabelecidos com organizações nacionais de outras ilhas, também não revela níveis relevantes. Por exemplo, são escassos os casos de geminação ou elaboração de projetos intermunicipais com a implicação de OTS similares. As condições de insularidade e fragmentação territorial do país, associadas aos elevados custos de deslocação inter-ilhas e aos constrangimentos financeiros das OTS dificultam o contacto e a interação assídua entre as OTS nacionais, pelo que também influenciam negativamente a expansão dessas ligações. O mesmo não sucede, porém, relativamente às suas relações com os membros da comunidade local - bonding capital. Em termos gerais as OTS nacionais estão bem enraizadas e gozam de alguma credibilidade nas suas comunidades, não obstante 
o aparente paradoxo com a baixa representatividade e participação dos seus membros associados e outros stakeholders na elaboração e execução das atividades.

A análise do conteúdo das entrevistas revelou que, além dos seus baixos índices, a influência do capital social para o desempenho das OTS também se afigura pouco reconhecida, uma vez que praticamente não esteve presente nas narrativas dos entrevistados que, pelo contrário, focalizaram-se constantemente na necessidade de se reforçar os meios humanos e financeiros.

\subsubsection{Capital financeiro}

Os entrevistados designaram a escassez de recursos financeiros para a prossecução das atividades e objetivos propostos como o maior obstáculo das OTS cabo-verdianas. Essas organizações reclamam recorrentemente, desde há alguns anos, a inexistência de mecanismos públicos nacionais, formalmente instituídos e/ou devidamente difundidos por meio de concursos anuais, para o apoio e financiamento das suas atividades. Só muito recentemente o Estado, através da publicação de uma Portaria ${ }^{3}$, veio dar vazão a essa reivindicação, estabelecendo as normas e os procedimentos a observar pelo Governo na atribuição de apoios financeiros às OTS que procuram "soluções para os problemas que afetam diferentes grupos da população em situação de carência, de risco e/ou de exclusão social".

O montante a ser concedido por cada organização nesse âmbito não pode ser inferior a duzentos mil ECV (1.800) e superior a seiscentos mil ECV (5.450€). Essa regulamentação não anulou, porém, os anteriores meios de subvenção de recursos públicos que desde há muitos anos lhes são atribuídos, preferencialmente por intermédio de protocolos com os mais variados ministérios e outras entidades governamentais, as Câmaras Municipais e, também, através do Programa Nacional de Luta Contra a Pobreza (PNLP), via assinatura de contratos-programa ou instituições de microcrédito. Mas o PNLP nunca abrangeu todas as ilhas e municípios, e embora o mais recente - que vigorará até o corrente ano, orçado em cerca de dois milhões de ECV (18.140€) - tenha sido estendido a mais regiões do país, deixou ainda de fora as ilhas do Sal e da Boa Vista.

Todavia, os entrevistados reconhecem que as OTS têm à mercê um amplo e diversificado leque de linhas de financiamento internacional, na generalidade outorgadas pela UE e seus Estados-membros, aos quais podem concorrer para executarem projetos de intervenção social. No entanto, a participação nesses concursos é inatingível para a maioria das OTS do país, desde logo porque as suas estruturas organizacionais e gestionárias são, no geral, incompletas e deficitárias, e quando confrontadas com os procedimentos exigidos pelos processos de candidatura não conseguem responder convenientemente. A necessidade de comparticipação financeira nos concursos e do domínio de línguas estrangeiras são as duas principais barreiras com se veem confrontadas quando pretendem usufruir desses recursos.

Acresce o facto de a maioria das OTS cabo-verdianas terem sido criadas propositadamente para obedecerem aos preceitos dos acordos de financiamento internacional - com que Cabo Verde tinha à disposição quando ainda detinha o estatuto de País Menos Avançado - ao invés de motivadas pela identificação e mitigação de vulnerabilidades sociais. Com a ascensão do país ao grupo dos Países de Desenvolvimento Médio em 2008, as OTS deixaram de beneficiar de algumas condições até então mais favoráveis, uma vez que a partir daí os fundos internacionais passaram a ser predominantemente concedidos diretamente ao apoio orçamental. Consequentemente apenas uma ínfima parte dessas OTS conseguiram resistir com relativa integridade à nova realidade. Enquanto algumas dissolveram-se, outras perderam autonomia e cederam ao isomorfismo institucional. Esse fenómeno é predominante no país e resulta particularmente de políticas e medidas assistencialistas impulsionadas por instituições públicas, privadas e partidos políticos que, frequente e, por vezes ardilosamente, elegem a simples doação de recursos financeiros a OTS como mecanismo de persuasão e representação na sociedade.

Conclui-se, deste modo, que não obstante as dificuldades no acesso ao financiamento por que passam praticamente a generalidade das OTS mundiais, as OTS nacionais cabo-verdianas têm acessíveis importantes fontes de recursos financeiros, na sua maioria internacionais, aos quais poderão concorrer e adquirir financiamento mediante a observância de certas condições. Condições essas que, no entanto, requerem organizações devidamente providas em termos de capital humano e capital social, dois requisitos que a generalidade das OTS nacionais ainda não possuem.

Essa conjuntura de debilidade de recursos e condições operacionais entre as OTS ajudam, portanto, a explicar o fraco dinamismo no campo do empreendedorismo social, tanto no setor turístico, como em geral. O estudo foi procurar detetar dinâmicas e condições favoráveis a esse tipo de atuação e encontrou essencialmente barreiras e inibições. Não obstante, encontrou também, da parte dos protagonistas entrevistados, o reconhecimento de potencial nas práticas de economia social e empreendedorismo 
social, e a perceção de que estes podem suportar formas alternativas de atuação num setor em que se reconhecem muitas deficiências e problemas. Isto apela a políticas mais favoráveis ao incentivo do empreendedorismo social.

\section{Conclusão}

Com base em asserções que enunciam o modelo de turismo de massas como fator determinante na emergência de desequilíbrios socioeconómicos em muitos países com potencialidades turísticas mas economicamente débeis, este exercício de investigação procurou explorar a noção de empreendedorismo social - admitido como um padrão de desenvolvimento sustentável, e, deste modo, um mecanismo para solucionar ou reduzir esses desequilíbrios - e as condições para a sua disseminação no contexto específico do turismo em Cabo Verde, e em particular, na ilha da Boa Vista, tendo na retaguarda as OTS como principais dinamizadoras.

Da análise ao contexto macrossocial, os resultados apontam para um quadro turístico cujos efeitos ambientais e socioeconómicos encerram um paradoxo. Isto é, embora o turismo seja valorizado e a sua relevância para o país largamente assumida, prevalece a ideia de que os seus benefícios são insuficientes para compensar os inconvenientes que ajuda a gerar.

Cabo Verde procedeu à abertura da sua economia ao capital e investimento estrangeiro e em virtude disso favoreceu o desenvolvimento progressivo do modelo turístico massificado que ali se assiste, mormente nas ilhas do Sal e da Boa Vista. No caso concreto da Boa Vista, que constituiu o principal objeto desse estudo, observou-se que a celeridade com que o setor privado determinou a implantação das estruturas básicas de receção turística, coincidiu, cumulativamente, com um cenário de impreparação do setor público e segregação da sociedade civil face às políticas de desenvolvimento em geral, e do turismo, em particular. Efetivamente, verificou-se que, em contraposição aos princípios e diretrizes da sustentabilidade turística, quer a opção de se apostar no turismo como alternativa de desenvolvimento, quer as ações inerentes à planificação e concretização desse processo, têm vindo a decorrer de uma estratégia centralizada nas instituições e organismos de poder público, que nos processos de tomada de decisão, esforça-se para atender e priorizar as pretensões das organizações privadas, mas não envolve, efetiva e amplamente, as populações locais.

Esta circunstância, a que se acrescenta o facto das atividades diretamente ligadas à cadeia produtiva do turismo estarem sob o controlo de um grupo restrito de operadores turísticos, a quem o senso comum vincula posicionamentos reservados e condutas raramente congruentes aos interesses da generalidade da população, têm vindo a condicionar a confiança e a propensão empreendedora no setor turístico, incluindo as iniciativas que possam se adequar à lógica do empreendedorismo social.

No entanto, os resultados obtidos revelam a presença de um conjunto de oportunidades e recursos ainda suscetíveis de serem valorizados com vista à complementaridade da oferta turística existente. Do mesmo modo, o empreendedorismo social é unanimemente visto como um instrumento oportuno para os potencializar e, simultaneamente, contribuir para a redução dos desequilíbrios socioeconómicos resultantes de um processo de desenvolvimento turístico acelerado, deficientemente planeado, e excessivamente concentrado.

O cenário e os problemas sociais atualmente vivenciados na Boa Vista desafiam e exortam por intervenção social, particularmente dos empreendedores sociais que, conforme se viu, são determinados e fascinados pela transformação de situações sociais manifestamente injustas e complexas. Para serem bem-sucedidas não bastam, porém, as potencialidades do setor turístico. Como a cadeia de produção turística da ilha da Boa Vista é relativamente fechada e dominada por operadores estrangeiros de grande dimensão, para entrarem nesse circuito e aí se manterem sustentáveis, as OTS terão que, antes de mais, terem estruturas organizacionais e recursos humanos competentes e verdadeiramente empreendedoras, e capazes de mobilizar os recursos externos.

No entanto, os resultados da análise ao nível microssocial levam a concluir que a grande maioria das OTS cabo-verdianas não dispõem desses requisitos, pelo que, no geral, ainda não reúnem as condições necessárias para fomentar e dinamizar a economia social e o empreendedorismo social no setor turístico. Relativamente ao item capital humano, as OTS caraterizam-se pelo elevado grau de voluntariedade e informalidade, fraca capacidade de liderança e baixos níveis de qualificação técnica das suas estruturas organizacionais e gestionárias. Também em relação ao capital social, os índices observados são baixos, pois, retratam reduzidos níveis de participação associativa, fraca dinâmica interventiva e capacidade de mobilização. Com baixos índices de capital humano e capital social, as OTS confrontam-se, por 
consequência, com limitações na mobilização de capital financeiro. Embora sem dados que possam permitir uma análise comparada entre as diferentes ilhas, os entrevistados identificam a Boa Vista como sendo a ilha com maiores insuficiências em termos de desempenho das OTS.

Com base nesses resultados, entende-se que, em Cabo Verde, é preciso partir de base, e por intermédio de um processo amplamente participativo, e estruturado numa abordagem bottom-up, construir um ambiente mais propício ao surgimento de iniciativas de empreendedorismo social no setor turístico.

\section{Bibliografia}

Afrobarometer

2015. Aumenta a percepção da corrupção em Cabo Verde. Retrieved from http://afrobarometer.org/press/ aumenta-percepcao-da-corrupcao-em-cabo-verde

Almeida, J.

2011. O essencial sobre o capital social. Lisboa: Imprensa Nacional Casa da Moeda.

Alvord, S., Brown, D., \& Letts, C.

2004. Social Entrepreneurship and Social Transformation: An Exploratory Study. The Journal of Applied Behavioral Science, 40(3), 260-282.

Austin, J., Stevenson, H., Wei-Skillern, J.

2006. Social and Commercial Entrepreneurship: Same, Different, or Both? Entrepreneurship Theory and Practice, 30(1), 1-22.

Bernardino, S., Santos, J. F.

2014. Perfil do empreendedor social em Portugal: O caso da Bolsa de Valores Sociais. Paper presented at the Seminário Empreendedorismo e Inovação, Oeiras, Porto.

Bornstein, D.

2005. Como mudar o mundo: Empreendedores sociais e o poder das novas ideias. Rio de Janeiro: Record. Brohman, J.

1996. New directions in tourism for third world development. Annals of Tourism Research, 23(1), 48-70. Brooks, A. C.

2008. Social entrepreneurship: A modern approach to social value creation. New Jersey: Pearson Prentice Hall.

Brouard, F., \& Larivet, S.

2009. Social entrepreneurship: Definitions and boundaries. Comunicação apresentada no ANSER-ARES 2009 Conference, Ottawa, Canada.

Butler, R. W.

1999. Sustainable tourism: A state-of-the-art review. Tourism Geographies: An International Journal of Tourism Space, Place and Environment, 1(1), 7-25.

Carvalho, J. M.

2008. Economia Solidária: Uma perspetiva sobre a experiência em Cabo Verde (Master's thesis, Universidade de Brasília). Retrieved from http://repositorio.unb.br/handle/10482/1411

Cunha, L.

2006. Economia e política do turismo. Lisboa: Editorial Verbo.

Dees, J. G.

2001. O significado do "empreendedorismo social", tradução de "The meaning of "social entrepreneurship", Center for the Advancemente of Social Entrepreneurship. Retrieved from http://www.uc.pt/feuc/ ceces/ficheiros/dees.

Ferreira, S.

2000. As organizações do terceiro sector na reforma da segurança social. In Atas do IV Congresso Português de Sociologia - Sociedade Portuguesa: Passados Recentes, Futuros Próximos. Coimbra 17-19 de abril de 2000. Lisboa: Associação Portuguesa de Sociologia (APS).

Ferreira, S.

2005. O que tem de especial o empreendedor social? O perfil de emprego do empresário social em Portugal. Oficina do CES, 223, 1-43.

Ferreira, S.

2006. Empreendedorismo social, profissionalização e emprego. Comunicação apresentada na Conferência - A Economia Social e a Promoção de Emprego, Observatório do Emprego e Formação Profissional (OEFP), Lisboa. 
Flick, U.

2009. Introdução à pesquisa qualitativa. Porto Alegre: Artmed.

Hill, G., \& Cooke, M.

2013. How do you build a community? Developing community capacity and social capital in an urban aboriginal setting. Pimatisiwin, 11(3), 421-432.

INECV

2015. Conta satélite do turismo 2011-2014. Praia: INECV.

Leadbeater, C.

1997. The rise of the social entrepreneur. London: Demos;

Mair, J., \& Martí, I.

2006. Social entrepreneurship research: A source of explanation, prediction, and delight. Journal of World Business, 41, 36-44.

Meneses, J. W.

2012. Liderança e gestão de organizações sem fins lucrativas. In C. Azevedo, R. C. Franco, \& J. W. Meneses (Eds.), Gestão das Organizações Sem Fins Lucrativos: O desafio da inovação social (pp. 135-161). Porto: Impulso Positivo.

Mignone, J., \& O’Neil, J.

2005. Conceptual understanding of social capital in First Nations Communities: An illustrative description. Pimatisiwin, 3(2), 7-44.

Miles, M. B., Huberman, A. M., \& Saldaña, J.

2014. Qualitative data analysis: a methods sourcebook. Los Angeles: Sage Publications.

Mourão, J. M.

2000. Desenvolvimento sustentável do turismo: Princípios, fundamentos e práticas. GeoINova, 2, 87-117.

Nicholls, A., \& Cho, A. H.

2006. Social entrepreneurship: The structuration of a field. In A. Nicholls (Ed.), Social entrepreneurship: New models of sustainable social change (pp. 99-118). New York: Oxford University Press.

Parente, C. (Ed.).

2014. Empreendedorismo social em Portugal. Porto: Universidade do Porto. Retrieved from http://web3. letras.up.pt/empsoc/index.php/e-book

Peredo, A. M., \& McLean, M.

2006 Social entrepreneurship: A critical review of the concept. Journal of World Business, 41(1), 56-65.

PLATONGS: Plataforma das ONG de Cabo Verde

2009. Código Ético das ONG'S e associações cabo-Verdianas de fim não lucrativo. Retrieved from http:// platongs.org.cv/index.php/relatorios-e-planos/outros/93--51

Portes, A.

2000. Capital social: Origens e aplicações na sociologia contemporânea. Sociologia - Problemas e Práticas, 33, 133-158.

Putnam, R.

1993. Making democracy work: Civic traditions in Modern Italy. New Jersey: Princeton University Press. Putnam, R.

1995. Tuning in, tuning out: The strange disappearance of social capital in America. PS: Political Science and Politics, 28(4), 664-683.

Saarinen, J.

2006. Traditions of sustainability in tourism studies. Annals of Tourism Research, 33(4), 1121-1140.

Santos, J.

2013. A economia social em Cabo Verde: Entre o público e o privado, uma via de autopromoção social e económica das populações mais desfavorecidas. Comunicação apresentada no Fórum Internacional - Proteção Social para Crescimento Inclusivo: Opções e Perspetivas, Praia, Cabo Verde.

Strauss, A., \& Corbin, J.

2008. Pesquisa qualitativa: técnicas e procedimentos para o desenvolvimento de teoria fundamentada. Porto Alegre: Artmed.

UECV: Delegação da União Europeia em Cabo Verde

2014. Cabo Verde: roteiro da UE para um compromisso com a sociedade civil - 2014-2017. Retrieved from http://eeas.europa.eu/delegations/cape_verde/documents/20150106-roteiro-da-ue-para-um-compromisso-com-a-sociedade-civil-2014-2017-cabo-verde_pt.pdf

UNWTO

2017. Tourism highlights: 2015 edition. Madrid: UNWTO. 
Woolcock, M., \& Narayan, D.

2000. Social capital: Implications for development theory, research, and policy. The World Bank Research Observer, 15(2), 225-249.

Young, R.

2006. For what it is worth: Social value and the future of social entrepreneurship. In A. Nicholls (Ed.), Social entrepreneurship: New models of sustainable social change (pp. 56-73). New York: Oxford University Press.

\section{Notas}

1 Regionalismo cabo-verdiano que se aplica quando um grupo de pessoas se junta voluntariamente por uma causa.

2 Segundo os dados do Afrobarometer (2015)

3 Portaria n. ${ }^{\circ} 27 / 2013$ de 17 de abril. 